\title{
Influence of Fly Ash on Surface Chloride Concentration Under Shallow Immersion Condition
}

\author{
Jun Liu, Xiaodong Wang, Feng Xing, and Ningxu Han \\ Guangdong Provincial Key Laboratory of Durability for Marine Civil Engineering, \\ College of Civil Engineering, Shenzhen University
}

\begin{abstract}
In this paper, the influence of fly ash content on concrete surface chloride concentration was investigated through periodical tests of surface chloride concentration of concrete by immersing three kinds of concrete specimens in $5.0 \mathrm{wt}$ \% sodium chloride solution. One kind of specimen is common concrete without fly ash, whereas the other two kinds of specimens are mixed with fly ash. The results show that the surface chloride ion concentration ranges from 0.295 to $0.777 \mathrm{wt}$ \% for the immersed concrete samples in this study; in the initial stage of immersion, the concrete surface chloride ion concentration is affected by added fly ash, and after 30 days of immersion, the surface chloride concentration of concrete with fly ash is 1.3 times that of concrete without fly ash at the same water-binder ratio; for the concretes without fly ash, the surface chloride concentration is linear with immersion time, whereas for the concrete with fly ash, the surface chloride concentration is nearly linear with square root of immersion time; for the concrete with fly ash, fly ash contents have little impact on the surface chloride concentration, and the surface chloride content of concrete without fly ash is gradually close to that of concrete with 15 and $30 \mathrm{wt} \%$ of fly ash.
\end{abstract}

Keywords: fly ash, chloride, immersion, model, concrete.

\section{INTRODUCTION}

The reinforced concrete is one kind of common building material. In general, reinforced concrete structures share the characteristics of good durability, low maintenance cost, and convenience. However, concrete is porous, which can allow environmental harm ion to transport into inner parts of structure, for example, for the reinforced concrete structures served in the chloride conditions, chloride ion, with strong penetrability, can deposit on the concrete surface followed by diffusing into internal concrete and then accumulate around steel reinforcement to over the critical concentration, inducing steel reinforcements to be corroded (Angst, Elsener, et al., 2009; Otieno, Beushausen, \& Alexander, 2014; Ryan \& O'Connor, 2013; Wang, Zeng, Wang, et al., 2014); therefore, the durability problems of concrete structures are caused. "In order of decreasing importance, the major causes concrete deterioration today are as follows: corrosion of reinforcing steel, frost action in cold climates, and physicochemical effects in aggressive environments," Professor Mehta pointed out in the report of "Durability of concrete-fifty years of progress" (Mehta, 1991). Chloride-induced corrosion of steel reinforcement is one of the most important reasons that lead to the failure of structures (The Institution of Civil Engineers, 1985).

Fly ash is widely used in concrete of practical projects. It has effects of reactivity, morphology, and tiny aggregate and can obviously improve the practice performance and corrosion resistance of concrete and reduce the early hydration heat of concrete (Han, Kim, et al., 2003; Haque, Langan, et al., 1984; Yoon, Monteiro, et al., 2014). Some researches (Kearslkya \& Wainwringht, 2002) show that fly ash can thin and block the micro pore in concrete to optimize the micro pore structure, which improves the concrete's ability to resist chloride ion erosion, thus the starting time of steel reinforcement will be delayed. Moreover, mixing up fly ash can replace partial cement, which plays a role in green environmental protection by reducing carbon emissions of construction.

The surface of concrete serves to protect the structure. Service environments of buildings physically and chemically erode structures from surface and then into internal concrete gradually, whereas compact surface layer can slow and even restrain the infiltration of harmful ions (Horgnies \& Willieme, 2011) to prolong the service life of structures. Chloride ions, in the environment, first deposit at surface of concrete and then are transported into internal concrete. In this paper, the deposition law of chloride ions at surface of fly ash concrete was investigated by soaking concrete with different proportions of fly ash in $\mathrm{NaCl}$ solution.

\section{MATERIALS AND METHODS}

\subsection{Materials}

Ordinary Portland cement (PO42.5, produced by Shenzhen Haixing Onoda Cement Co., Ltd), fly ash 
(Class I, from Shenzhen Mawan Power Plant), and $\mathrm{NaCl}$ (purity over 99\%) were used in this study.

\subsection{Samples}

The samples were prepared with water to binder ratio $\mathrm{W} / \mathrm{C}=0.47$ in three proportions (Table 1). The effect of mineral admixtures was considered, and fly ash substitutes cement with 15 and $30 \%$ by weight.

Table 1. Composition of the studied samples of normal strength concrete with fly ash additives $\left(\mathrm{kg} / \mathrm{m}^{3}\right)$.

\begin{tabular}{lccccc}
\hline Sample & PO & Sand & Stone & Fly Ash & Water \\
\hline CF0 & 409 & 720 & 1079 & 0 & 192 \\
CF15 & 348 & 697.3 & 1054 & 61.35 & 192 \\
CF30 & 286.3 & 689 & 1041 & 122.7 & 192 \\
\hline
\end{tabular}

\subsection{Experiment methods and procedures}

\subsubsection{Natural immersion method}

The concrete samples were cured for 28 days in standard conditions and then were immersed in $\mathrm{NaCl}$ solution, in accordance with AASHTO T259 (Standard Method of Test for Resistance of Concrete to Chloride Ion Penetration), as shown in Figure 1. One smooth surface of concrete was selected as the penetration area, and the other five surfaces were sealed with paraffin wax. The concentration of $\mathrm{NaCl}$ solution was $5 \%$ in mass. The soaking periods were set as 30,60, 90,120, and 150 days.

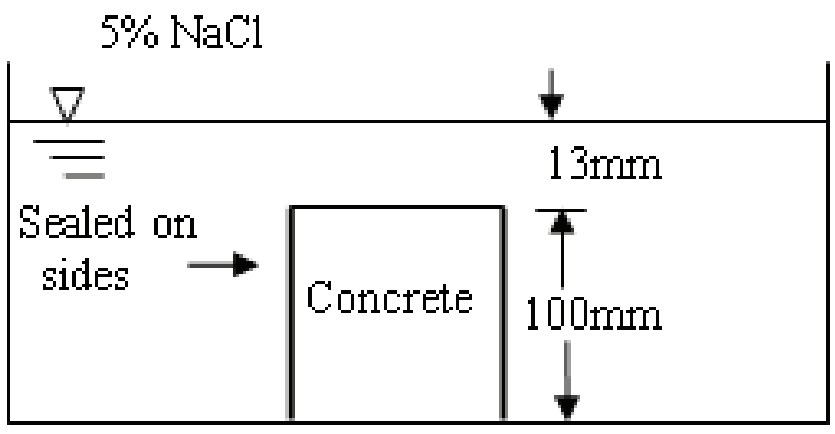

Figure 1. AASHTOT259 of chloride ion diffusion.

\subsubsection{Deposition of free chloride ions}

At any prescribed soaking age, the specimens were taken out from the solution, followed by being put in room until they got dried at room temperature around $20 \pm 2^{\circ} \mathrm{C}$. The cumulative amount of chloride ion was measured using the methods of stratified sampling and chemical analysis. The specimens were cut into slices (around $5 \mathrm{~mm}$ in thickness) from the penetration surface, namely, $0-5,5-10,10-15,15-20$, and 20-25 mm by depth. In that method, average contents of chloride ion of slices represent the concentration of chloride ion at the depth of $2.5,7.5,12.5,17.5$, and $22.5 \mathrm{~mm}$ respectively. The slices were crushed into small particles less than $0.63 \mathrm{~mm}$ with removing coarse aggregate. Contents of water-soluble chloride ion were measured by water-solubilizing extraction, and the results are regarded as deposition amount of free chloride ion.

\section{EXPERIMENTAL RESULTS AND DISCUSSION}

\subsection{Deposition amount of chloride ion at concrete surface}

Surface chloride ion contents at prescribed soaking age are shown in Table 2.

Table 2. Surface chloride ion contents at prescribed soaking age $/ \%$ relative to mortar.

\begin{tabular}{lccccc}
\hline Sample & \multicolumn{5}{c}{ Soaking Age/Day } \\
\cline { 2 - 6 } & $\mathbf{3 0}$ & $\mathbf{6 0}$ & $\mathbf{9 0}$ & $\mathbf{1 2 0}$ & $\mathbf{1 5 0}$ \\
\hline CF0 & 0.295 & 0.408 & 0.450 & 0.679 & 0.684 \\
CF15 & 0.397 & 0.505 & 0.630 & 0.752 & 0.790 \\
CF30 & 0.397 & 0.576 & 0.625 & 0.700 & 0.777 \\
\hline
\end{tabular}

\subsection{Influence of fly ash on the deposit of chloride ion at concrete surface}

The transport process of chloride is strongly affected by microstructure of concrete, and the introduced fly ash can change the concrete's microstructure, which can influence the deposit of chloride at concrete surface. The bar chart, Figure 2, indicates the surface chloride contents of three kinds of samples in question at prescribed soaking age.

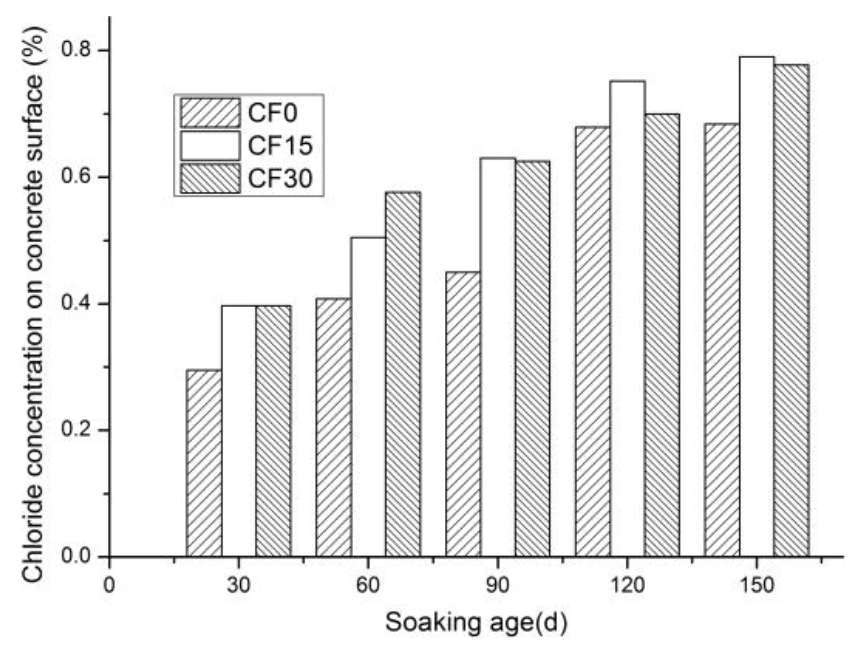

Figure 2. Surface chloride contents of sample in question at prescribed soaking age.

Typically, the effect of fly ash can be regarded as the complex of three effects, namely reactivity effect of pozzolana, tiny aggregate effect, and morphological effect of powder. Reactivity of pozzolana is chemical reaction, and the other two effects are physical functions. Pozzolanic activity of fly ash is one kind of potential chemical activity, which can only express 
under the effect of activator. The calcium hydroxide is the most common activator, and hydration of Portland cement can produce calcium hydroxide activator in paste, which is an effective exciting method without any extra treat or activators. However, the solubility of calcium hydroxide is lower, and $\mathrm{Ca}^{2+}$ is inferior to alkali metal ions in alkalinity, so the limited exciting value of calcium hydroxide cannot have the pozzolanic activity of fly ash reached a fairly high degree, especially in early stage of hydration process when the degree of calcium hydroxide-activated pozzolanic reaction of fly ash is very low, which results in a slow hydration of fly ash concrete. According to Figure 2, surface chloride contents of CF15 and CF30 are as 1.3 times as that of CFO at 30 days of soaking age. This is principally because fly ash reduces the quantity of active material in paste, which delays the hydration process of cement paste. What can also been seen from Figure 2 is that surface chloride contents of CF15 and CF30 are roughly the same, revealing that the extent of mixed fly ash in question has a slight influence on the surface chloride ion concentration. Furthermore, as the soaking time increases, the concrete without fly ash progressively approaches to fly ash concrete in surface chloride ion content. This is because the pozzolanic effect of fly ash progressively emerges and surface layer of concrete becomes more compact, making deposit of chloride ion difficult for surface of CF15 and CF30.

\subsection{Fitting the surface chloride concentration with different equations}

For the practical concrete structures, surface concrete concentration is not constant but time dependent. Amey, Johnson, et al. (1998) support that chloride concentration at concrete surface is linear with service time:

$$
c=k t
$$

where $c$ is the chloride ion concentration on the surface, $k$ is a constant under a linear buildup condition, and $t$ is the time of exposure.

If it is considered that surface chloride ion concentration is linear with square root of time, the case is as follows:

$$
c=k t^{0.5}
$$

where $k$ is a constant under a square root buildup condition.

Table 3. Results of fitting with different equation.

\begin{tabular}{lclc}
\hline Concrete & Equation & Equation Fitting & $\boldsymbol{R}^{\mathbf{2}}$ \\
\hline \multirow{2}{*}{ CF0 } & 1 & $y=0.1885+0.0035 x$ & 0.901 \\
& 2 & $y=0.0619 \times 0.5-0.0647$ & 0.886 \\
\hline \multirow{2}{*}{ CF15 } & 1 & $y=0.3049+0.0034 x$ & 0.969 \\
& 2 & $y=0.0616 \times 0.5+0.0495$ & 0.981 \\
\hline \multirow{2}{*}{ CF30 } & 1 & $y=0.3498+0.0030 x$ & 0.928 \\
& 2 & $y=0.0533 \times 0.5+0.1258$ & 0.968 \\
\hline
\end{tabular}

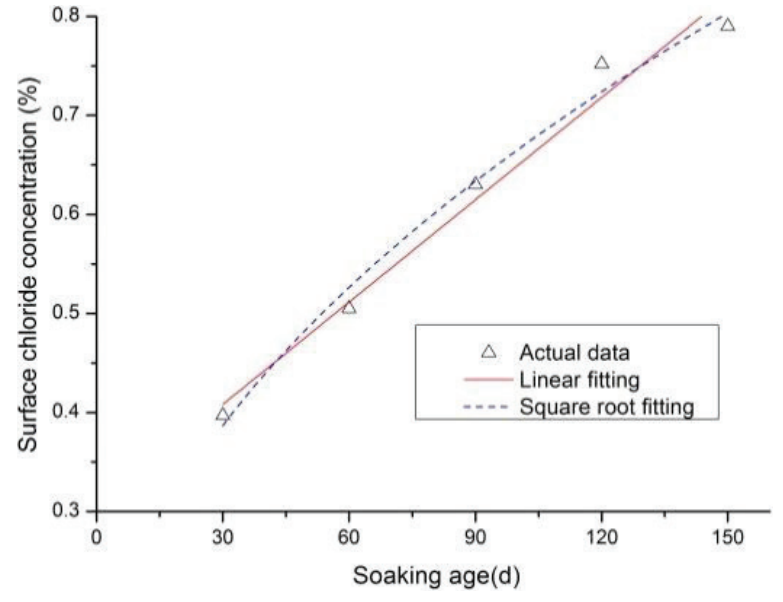

(a) CFO

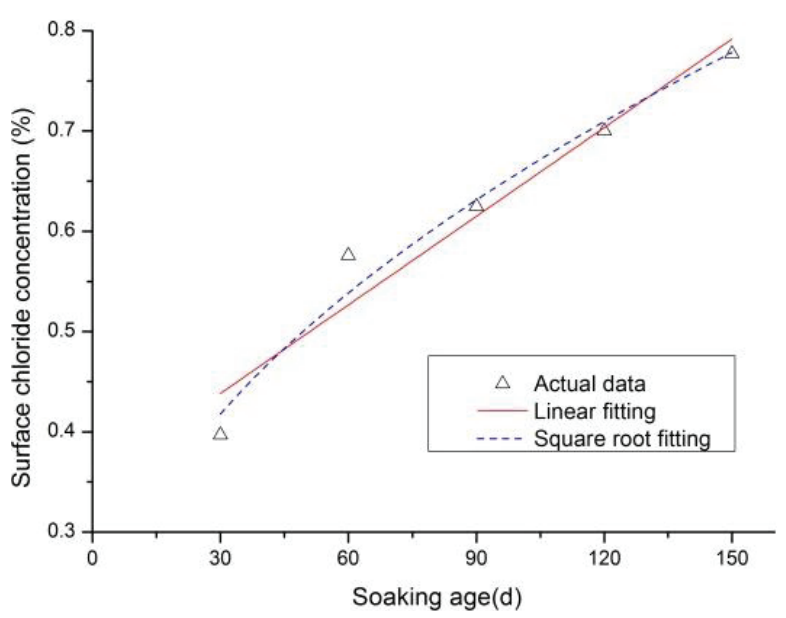

(b) CF15

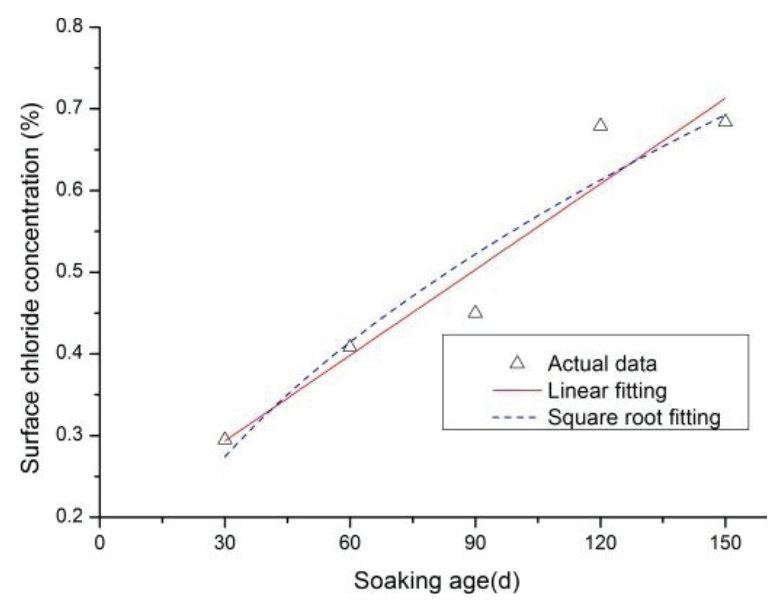

(c) CF30

Figure 3. Fitting curves of surface chloride ion concentration for samples in question: (a) CF0, (b) CF15, and (c) CF30.

The experimental data of surface chloride ion are fitted with Equations (1) and (2), and the results are shown in Table 3 and Figure 3 . Table 3 shows that correlation coefficients of fitting with Equation (1) for 
CF0, CF15, and CF30 are 0.901, 0.969, and 0.928, respectively, and that with Equation (2) for CF0, CF15, and CF30 are $0.886,0.981$, and 0.968 , respectively. It is clear, according to correlation coefficients, surface chloride ion concentration of CFO (concrete without fly ash) is more close to time of exposure, whereas for CF15 and CF30 (fly ash concrete), Equation (2) is more applicable.

\subsection{Influence of fly ash on microstructure of concrete}

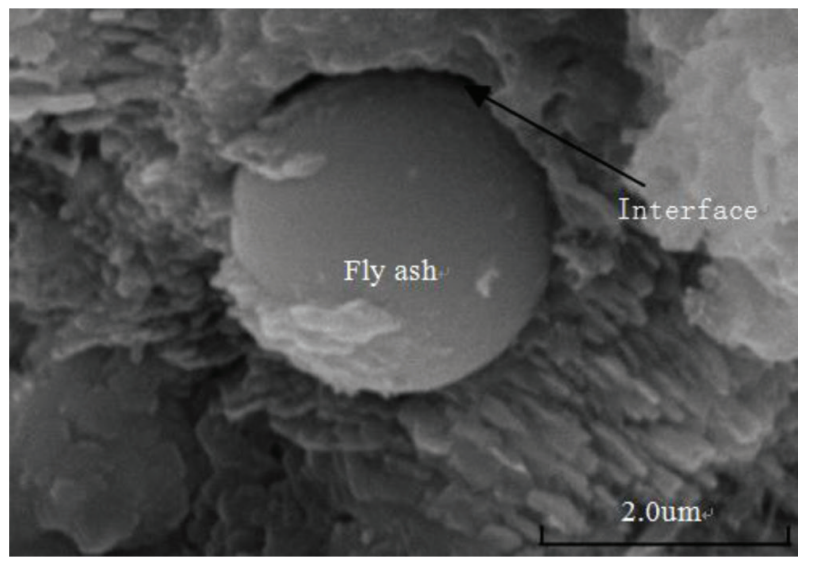

Figure 4. SEM pictures of CF15 at 30 days of soaking age.

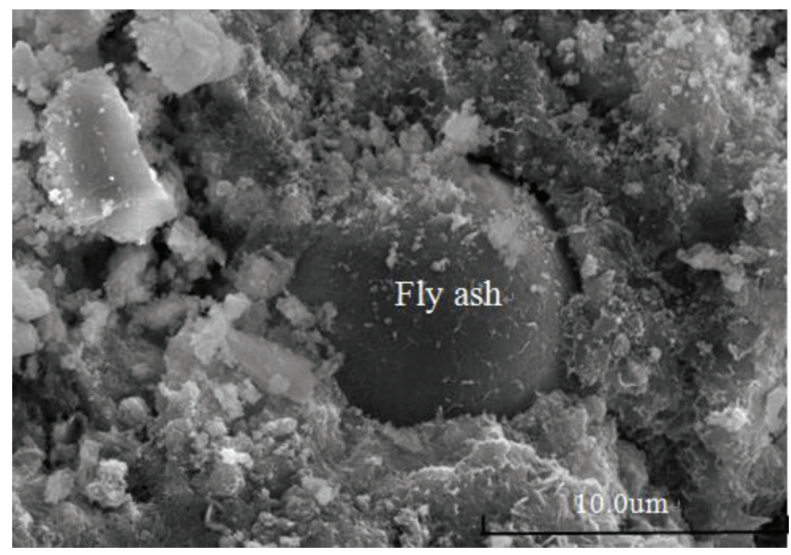

Figure 5. SEM pictures of CF15 at 90 days of soaking age.

In early stage of hydration, fly ash mainly functions as fill. As shown in Figure 4, there exist micro cracks between fly ash powders and cement paste. Moreover, effective W/C, dominating the hydration rate of cement, relatively increases with the decrease of proportion of cement clinker, owing to the mixed fly ash that replaces partial cement. Due to the increase of effective W/C, concentration of $\mathrm{Ca}^{2+}$ in solution reduces, which slows the total hydration rate of cement-fly ash system. Consequently, hydration products cannot connect closely enough with each other, and this causes the increase to surface chloride. As shown in Figure 5, after 90 days of soak, fly ash is well knit with cement paste, optimizing the pore structure of concrete. Mehta and Manmohan (1980) show that there exists a relationship between permeability and distribution of pore size and the pores of over $132 \mathrm{~nm}$ control the permeability of concrete to a great extent. Under natural soak environment of chloride, with the increase of age, fly ash gradually plays the effect of optimizing pore structure of concrete to reduce the porosity and amount of intercommunicating pore, therefore, the ability of chloride resistance is improved, which makes deposition difficult for chloride on concrete surface. This also explains why surface chloride concentration of common concrete (CF0) progressively approaches to that of fly ash concrete (CF15 and CF30) with the increase of soaking age.

\section{CONCLUSION}

Under the condition of soak in $\mathrm{NaCl}$ solution, the range of surface chloride ion concentration relative to paste is $0.295-0.777 \%$ for the concrete in question.

Surface chloride ion concentration of CFO (concrete without fly ash) is more close to time of exposure, whereas, for CF15 and CF30 (fly ash concrete), surface chloride ion concentration is more close to the square root of exposure time.

In early age of soak, fly ash considerably affects the deposit of chloride. At 30 days of soak age, CF15 and CF30 are 1.3 times of CFO in surface chloride ion. Moreover, mixed volume of fly ash in question has a slight influence on deposition of chloride. For the long soak age, CF0, CF15, and CF30 tend to a same level of surface chloride concentration.

\section{ACKNOWLEDGMENTS}

The financial supports from National Basic Research Program of China (2011CB013604), Natural Science Foundation ofChina(51108271), Shenzhen City Science and Technology Project (JCYJ20120613115622154), and National Natural Science Foundation of China (51120185002) are greatly acknowledged.

\section{REFERENCES}

Amey, S. L., Johnson, D. A., Miltenberger, M. A., \& Farzam, H. (1998). Predicting the service life of concrete marine structure: An environmental methodology. ACI Structural Journal, 95(1), 27-36.

Angst, U., Elsener, B., Larsen, C. K., \& Vennesland, O. (2009). Critical chloride content in reinforced concrete: A review [J]. Cement and Concrete Research, 39(12), 1122-1138.

Han, S.-H., Kim, J.-K., \& Park, Y.-D. (2003). Prediction of compressive strength of fly ash concrete by new 
apparent activation energy function. Cement and Concrete Research, 33, 965-971.

Hague, M. N., Langan, B. W., \& Ward, M. A. (1984). High fly ash concretes. ACl Structural Journal, 81(1), 54-60.

Horgnies M., \& Willieme, P. (2011). Influence of the surface properties of concrete on the adhesion of coating: Characterization of the interface by peel test and FT-IR spectroscopy. Progress in Organic Coatings, 72, 360-379.

Kearslkya, E. P., \& Wainwringht, P. J. (2002).The effect of porosity on the strength of foamed concrete. Cement and Concrete Research, 32(2), 233-239.

Mehta, P. K. (1991). Durability of concrete-fifty years of progress. Proceeding of 2nd International Conference on Concrete Durability. Detroit: ACI SP126-1, pp. 1-31.

Mehta, P. K., \& Manmohan, D. (1980). Pore size distribution and permeability of hardened cement pastes. Proceedings of 7th International Conference on Chemistry of Cement. Paris: [sn], pp. 1-5.
Otieno, M., Beushausen, H., \& Alexander, M. (2014). Effect of chemical composition of slag on chloride penetration resistance of concrete. Cement and Concrete Composites, 46, 56-64.

Ryan, P. C., \& O'Connor, A. J. (2013). Probabilistic analysis of the time to chloride induced corrosion for different self-compacting concretes. Construction and Building Materials, 47, 1106-1116.

The Institution of Civil Engineers. (1985). How to Make Today's Concrete Durable for Tomorrow. London: The Institution of Civil Engineers, 87pp.

Wang, Z., Zeng, Q., Wang, L., Yao, Y., \& Li, K. (2014). Corrosion of rebar in concrete under cyclic freeze-thaw and chloride salt action. Construction and Building Materials, 53, 40-47.

Yoon, S., Monteiro, P. J. M., Macphee, D. E., Glasser, F. P., \& Imbabi, M. S. E. (2014). Statistical evaluation of the mechanical properties of highvolume class $\mathrm{F}$ fly ash concretes. Construction and Building Materials, 54, 432-442. 